\title{
Sobre "la presentación de la persona en la vida cotidiana" de Erving Goffman: una comprensión de la teoría social para su aplicación en la educación
}

Goffman, E. (1981). La Presentación de la persona en la vida cotidiana (H. Torres y F. Setaro, Trad.; 1a. ed.) Amorrortu Editores. (Obra original publicada en 1959).

Gladys de los Ángeles Romero Aguirre Universidad Juárez Autónoma de Tabasco gladys.romero@ujat.mx

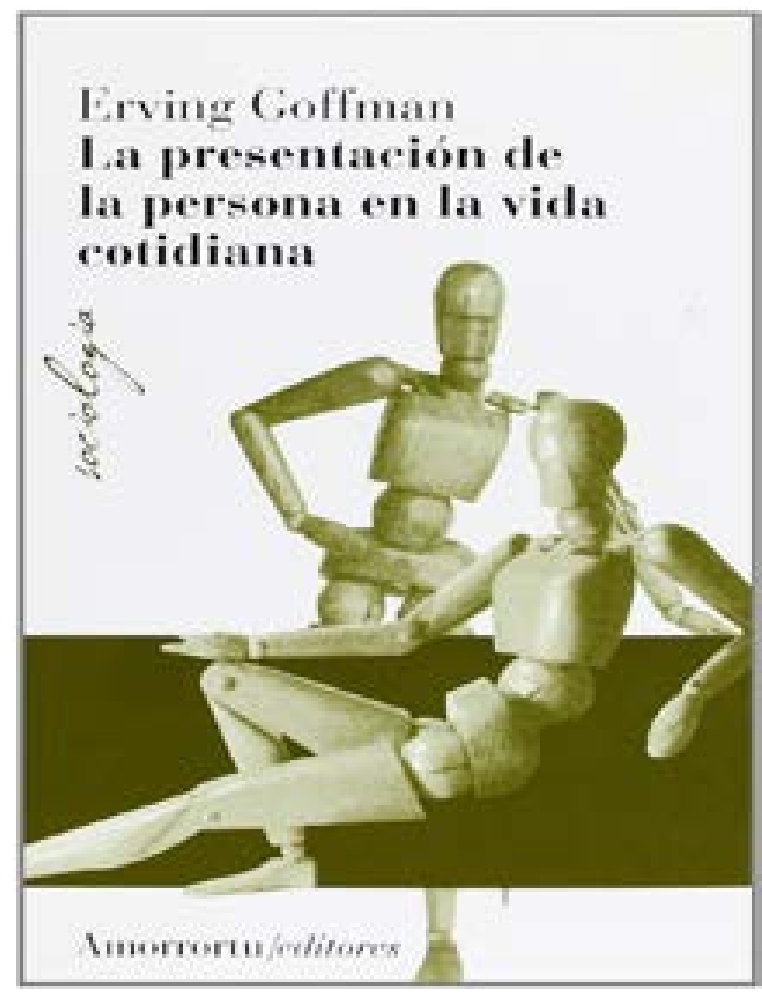
México

\section{| Resumen}

En este libro clásico de la sociología (Goffman, 1959/1981) nos habla sobre la perspectiva del autor hacia la vida cotidiana. Es una visión sociológica particular que analiza la manera que el ser humano se organiza en sociedad, cómo se percibe y percibe al otro, y cómo estas percepciones compartidas modifican nuestro desempeño social. Goffman hace una alegoría a la teatralidad, el individuo se representa a sí mismo y con base a la percepción que dicha representación genera en el otro.

\section{| Evaluación del documento que se reseña}

Para poder entender los fenómenos sociales en el ámbito educativo, independientemente del modelo teórico o metodológico a evaluar, es imperativo para el investigador comprender la forma en cómo los sujetos que interactúan en ese ámbito en el que se desenvuelven. Los clásicos de la sociología como el que reseñamos, son un claro ejemplo de cómo la interdisciplinariedad nos ayuda a entender los complejos sistemas sociales como la escuela.

Los investigadores novatos podemos realizar diversos trabajos con la mira fija solamente en nuestro problema de investigación, dejando a un lado el contexto de estudio por los datos que necesitamos para sostener o refutar nuestras hipótesis. Esa perspectiva ingenua nos puede limitar de información importante con el potencial de enriquecer nuestros hallazgos y es justo en ese punto donde Erving Goffman es de gran utilidad.

Emerging Trends in Education e ISSN: 2594-2840

Volumen 4, Número 8A, Enero-Junio 2022
Recibido:

08/02/2021
Aceptado:

20/05/2021
Publicado:

05/01/2022 
Erving Goffman es un sociólogo canadiense conocido como el padre de la microsociología. Su interés principal de estudio es el de la interacción de unidades mínimas o grupos reducidos, ubicándose en el campo del interaccionismo simbólico. El estudio que analizaremos es un clásico de la sociología, se denomina "La presentación de la persona en la vida cotidiana" publicado en su primera edición en inglés en 1959. La primera edición en castellano fue realizada en 1981, veinte años después.

Según Galindo (2015), a partir de esta publicación, la carrera de Goffman fue en ascenso, convirtiéndose así en un clásico a la altura de otros autores de referencia como Theodor W. Adorno y Jürgen Habermas. Esta sociología de la vida cotidiana abarca también la vida educativa, parte importante de cualquier sociedad. Esto justifica que independientemente de los años desde su publicación, su visión aún sea aplicable a la realidad actual del aula.

Para Goffman "cuando un individuo llega a la presencia de otros, estos tratan por lo común de adquirir información acerca de él o de poner en juego la que ya poseen" (1959/1981, p. 13). Esto es importante, ya que al estudiar los fenómenos educativos tendremos, sin duda, que estudiar los fenómenos sociológicos, las interacciones que ocurren, y todos los sujetos que se relacionan en el entorno escolar. Debemos considerar a todos los actores: maestros, alumnos, padres de familia y autoridades educativas. Todas estas figuras tienen un rol determinado, una expectativa interna y externa depositada en cada uno de estos roles y, sobre todo, tienen un sujeto "actor" de dicho rol, que lo ejecuta con base a sus expectativas. Esta actuación o representación teatral es la que estudia Goffman; él consideraba que esta visión era aplicable a cualquier establecimiento social concreto, en este caso, la escuela.

Entonces, el escenario teatral es el aula: el aula presencial, el aula virtual, el aula en sus diferentes formas y tamaños. Los actores principales serán los maestros y los alumnos. Pensemos en una clase presencial tradicional de nivel medio superior, por ejemplo. El maestro entra a clase con una expectativa clara de lo que se espera de él y lo que espera de los alumnos. Los alumnos por igual, incluso al ser la primera clase ya saben que esperar del maestro porque antes han tenido otros. Los alumnos son el público, pero al mismo tiempo lo son los padres y las autoridades de la institución; son público que algunas veces interactúa y otras no, pero que el maestro siempre toma en consideración.

Estos tres participantes, maestros, alumnos y público desempeñan un papel en el rol educativo. Todos tienen metas y objetivos, y dichos papeles pueden irse modificando si el objetivo de uno o del otro no se está alcanzando como se deseaba.

Improvisan. Esta improvisación se da porque cada vez que estamos en representación, algo se espera de nosotros y nosotros esperamos algo del otro. El maestro espera respuesta de sus alumnos (en el aula virtual, al menos se espera que el alumno esté atento a la clase y no haciendo otra actividad), espera quizá acuse de recibo del entendimiento sobre lo enseñado. El alumno espera que el maestro domine el tema que está enseñando, y toda esta interacción se repite una y otra vez en una sola clase. Si el maestro no contesta una pregunta de un alumno puede dar la impresión de no saber del tema y con ello, derribar las expectativas y fantasías de los alumnos sobre el saber del maestro, lo que puede orillar a desmotivar la curiosidad del estudiante, y demeritar la figura de poder del maestro ante la visión de los alumnos.

En el aula entonces, vivimos por inferencia, nos retroalimentamos continuamente de lo que emanamos en ella $\mathrm{y}$ viceversa. Todos los maestros también esperamos algo de ciertos alumnos y no de otros. ¿Por qué razón? Por la interacción constante con ellos. 
Goffman, con esta analogía enriquecedora que migra del

ámbito teatral al estudio social nos permite entonces poder analizar los fenómenos con una visión más incluyente y holística. En palabras de Roiz (2001), Goffman nos explica como los seres humanos manejamos nuestra identidad frente a los otros según el entorno en el que nos encontremos.

En conclusión, los investigadores debemos tener conciencia de esta infinita interacción al momento de acercarnos a estudiar el aula y sus actores. Entender que los actores educativos viven inmersos en un proceso comunicativo que puede cambiar constantemente en ese "juego de la información", se mantienen fachadas de uno y otro bando con un solo fin, el de lograr los objetivos instruccionales por un lado y por el otro aprobar un grado más.

\section{| Referencias}

Roiz, M. (2001). Reseña de "Sociologías de la situación" de E. Goffman, H. Sacks, A. Cicourel y M. Pollner. Revista Española de Investigaciones Sociológicas, (94), 219227. https://cutt.ly/oCvVcV4

Galindo, J. (2015). Erving Goffman y el orden de la interacción. Acta sociológica, (66), 11-34. https://doi.org/ $\underline{\mathrm{f} g} \mathrm{~g} 6 \mathrm{x} 5$ 